\title{
Câncer e trombose: uma revisão da literatura
}

Cancer and thrombosis: a literature review

\author{
Ernesto de Meis', Roger Abramino Levy²
}

\section{Resumo}

Desde a teoria de Trusseau, sobre a coagulação, até os dias atuais, muitas informações surgiram sobre a coagulação sanguínea. Com o melhor conhecimento dos eventos relacionados, através de estudos moleculares, celulares e clínicos, foi acordado que a formação do coágulo não era um fenômeno isolado, mas faz parte de um conjunto de eventos que, além de correlacionarem-se entre si, também interferem na biologia das células. Atualmente, esse intercâmbio entre o sistema hemostático e as células normais e patológicas mostrou ter um papel importante na gênese e na evolução de diversas doenças comuns e, nesse contexto, grande ênfase se dá para as neoplasias e sua biologia. O presente artigo tem como objetivo analisar a nova teoria da coagulação sanguínea e sua regulação, além de mostrar como esta interfere ao nível da biologia celular na célula neoplásica e na evolução clínica do paciente portador de câncer. O modelo de uma das condiçōes clínicas mais freqüentes, para demonstrar a conseqüência dessa interferência, é o aparecimento da trombose.

Palavras-chave: Câncer; Coagulação; Trombose 


\section{INTRODUÇÃO}

A trombose, entidade reconhecida e estudada há mais de 150 anos, vem ocupando lugar de destaque na evolução de inúmeras doenças. $\mathrm{O}$ grande impacto ocorreu quando a hipercoagulabilidade, antes considerada como responsável apenas pelos eventos clínicos de oclusão vascular, assumiu um papel mais amplo, incluindo o controle do ciclo celular e da neoangiogênese.

A incidência anual de trombose venosa profunda (TVP) em crianças (em relação às causas de morbidade e mortalidade) é de 1:100.000; contudo, esta relação vai se reduzindo, chegando a 1:100 em pessoas com idades avançadas ${ }^{1}$.

O estado de hipercoagulabilidade, responsável pelo aumento na freqüência dos eventos trombóticos, pode ser hereditário ou adquirido (quadro 1). Deve-se levantar a hipótese de herança genética trombofílica em pacientes com tromboses venosas graves recorrentes, história familiar de trombose, idade $\leq 45$ anos no primeiro evento trombótico, ou a presença de trombose sem fator de risco aparente, assim como em mulheres com história de abortos múltiplos ou partos prematuros. Por sua vez, o estado adquirido deve ser pensado nos pacientes restritos ao leito por tempo prolongado, pacientes submetidos a grandes cirurgias e na presença de doenças auto-imunes ou neoplasias ${ }^{1,2}$.

Virchow, em 1856, publicou uma teoria que se tornou clássica em relação à fisiopatologia da coagulação e trombose ${ }^{3}$. Em seu artigo, foram citados mecanismos trombogênicos, tais como: injúria vascular, estase sanguínea e modificação na composição do sangue. A teoria de Virchow, à medida que novos conhecimentos foram adquiridos na área, tem sofrido revisōes e modificaçôes, mas mantém grande parte de seus princípios inalterados. Assim, nos dias de hoje, é explicada pela tríade: mudanças indesejáveis na função celular do endotélio vascular (que Virchow denominava de injúria vascular); desequilíbrio no sistema prócoagulante (ativação dos fatores de coagulação) e no sistema anticoagulante (inibidor da ativação da coagulação e promotor da lise de coágulos e fibrinólise), que Virchow denominava como modificação na composição do sangue; e, finalmente, a ativação plaquetária $^{3}$. A estase, terceiro evento na tríade de

Quadro 1. Fatores de risco inerentes e adquiridos para o aparecimento de tromboses

\begin{tabular}{|l|l|}
\hline \multicolumn{1}{|c|}{ Características } & \multicolumn{1}{c|}{ Fatores de risco } \\
\hline $\begin{array}{l}\text { Adquiridas e possíveis de } \\
\text { interferência }\end{array}$ & Cirurgia \\
& Trauma \\
& Imobilização prolongada \\
& Uso de anticoncepcionais \\
& Reposição hormonal \\
& Tabagismo \\
& Gravidez e pós-parto \\
\hline Adquiridas e impossíveis de & Idade avançada \\
\hline interferência & Doenças mieloproliferativas \\
& Trombose prévia \\
& Resistência à proteína C não relacionada à mutação do gene \\
& Anticorpos antifosfolipídeos \\
& Homocistenúria leve à moderada \\
\hline Hereditários freqüentes & Mutação no gene do fator V (Fator V de Leiden) \\
& Mutação no gene da protrombina (fator II) \\
& Mutação homozigótica no gene da metilenotetrahidrofolato \\
& redutase \\
\hline Hereditários pouco freqüentes & Deficiência de antitrombina III \\
& Deficiência de proteína C \\
\hline Hereditários muito raros & Deficiência de proteína S \\
\hline & Disfibrinogenemias \\
\hline Homocistenúria homozigótica \\
\hline Humento nos níveis de fatores VIII e IX fibrinogênio \\
\hline
\end{tabular}

Fonte: Seligsohn et al., 2001. 
Virchow, é amplamente aceita por diversos autores ${ }^{4,5} \mathrm{e}$ questionada por outros ${ }^{3}$, permanecendo, assim, um assunto em debate.

Estima-se que cerca de $15 \%$ dos pacientes com neoplasia terão o diagnóstico de evento trombótico durante a evolução da doença. Esta, no entanto, é uma avaliação subestimada, uma vez que estudo em necropsias mostrou a presença de trombose em $50 \%$ dos pacientes que não tiveram o diagnóstico clínico de trombose no pré-morte $^{4,5}$. A freqüência de trombose também está relacionada amplamente com a evolução da neoplasia (quando mais avançada, mais freqüente) ${ }^{6-9}$, sendo considerada a segunda causa mais freqüente de óbito em pacientes com câncer ${ }^{4,5}$. Uma meta-análise de estudos com necropsias mostrou que o tromboembolismo pulmonar (TEP) foi causa de óbito em 8\%-35\% dos pacientes, e contribuiu no êxito fatal em pelo menos $45 \%$.

Um fato alarmante veio de estudo inglês, no qual, em 79.733 óbitos descritos como secundários à neoplasia, na realidade, em 7.500 a real causa de morte foram eventos de embolia pulmonar fatal que poderiam ter sido evitados.

No entanto, apesar das alteraçoes hemostáticas levando a hipercoagulabilidade a ocorrer em $60 \%$ a $100 \%$ dos pacientes, a freqüência de trombose nos diferentes tipos de tumores não é a mesma. Determinadas neoplasias, tais como: leucemia prómielocítica, leucemia monocítica aguda, tumores de pâncreas, pulmão e gliomas parecem ter maior incidência de fenômenos trombóticos clínicos ${ }^{4,5,7,9,10}$.

\section{HEMOSTASIA NORMAL}

A hemostasia sanguínea normal (Figuras 1-3) se faz através de um balanço entre dois sistemas que agem na coagulação. O primeiro, denominado de sistema prócoagulante, induz a formação do trombo, enquanto o segundo - sistema anticoagulante, composto por proteínas inibidoras da coagulação (antitrombina III, proteínas $\mathrm{C}$ e S) e pelo sistema fibrinolítico (que destrói a fibrina formada antes que seja produzido o coágulo) inibe a formação do coágulo ${ }^{11}$.

A coagulação normal pode ser dividida em três fases: a fase de iniciação, seguida da propagação e da amplificação ${ }^{12}$. A ativação da coagulação, no entanto, se faz em nível plaquetário e endotelial, o que faz sentido, uma vez que, deste modo, a reação torna-se restrita (se ocorresse no plasma haveria disseminação e trombose).

\section{HEMOSTASIA PRIMÁRIA}

Em situações em que não ocorre injúria ou estresse endotelial, normalmente não ocorre agregação plaquetária. Este efeito é devido a vários mecanismos

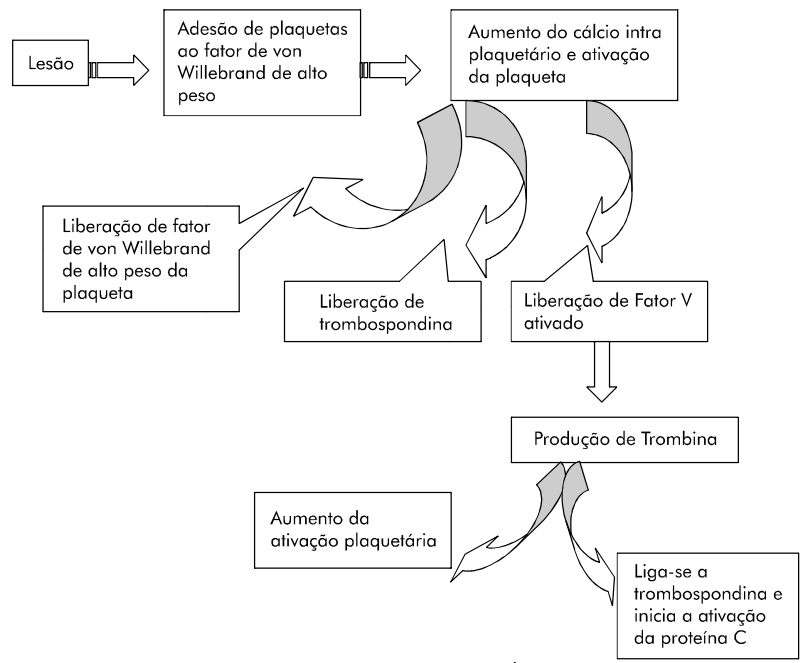

Figura 1. Hemostasia sanguínea normal

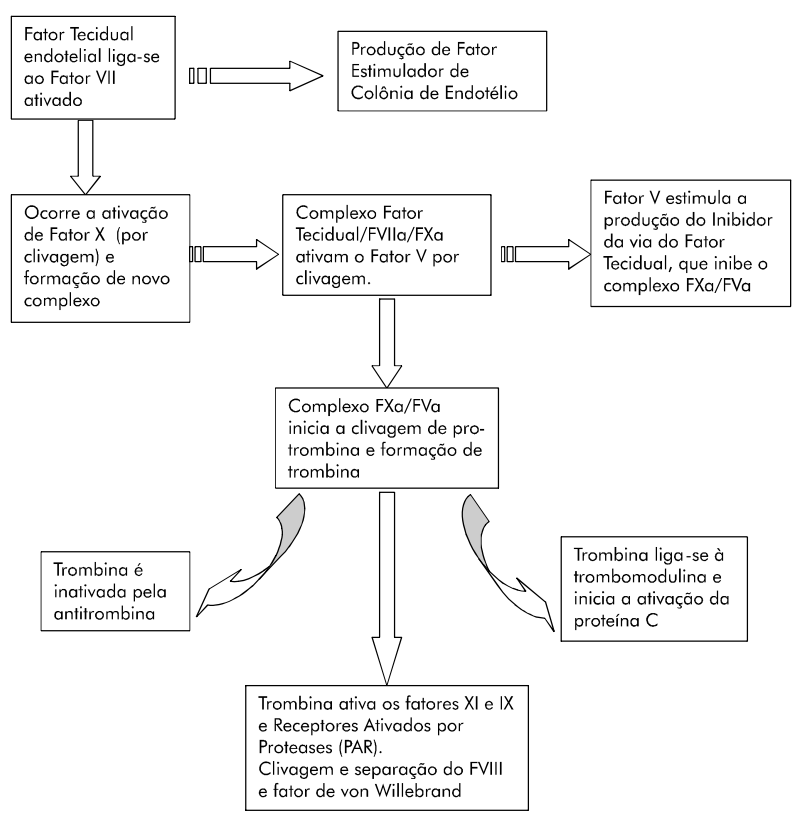

Figura 2. Hemostasia sanguínea normal

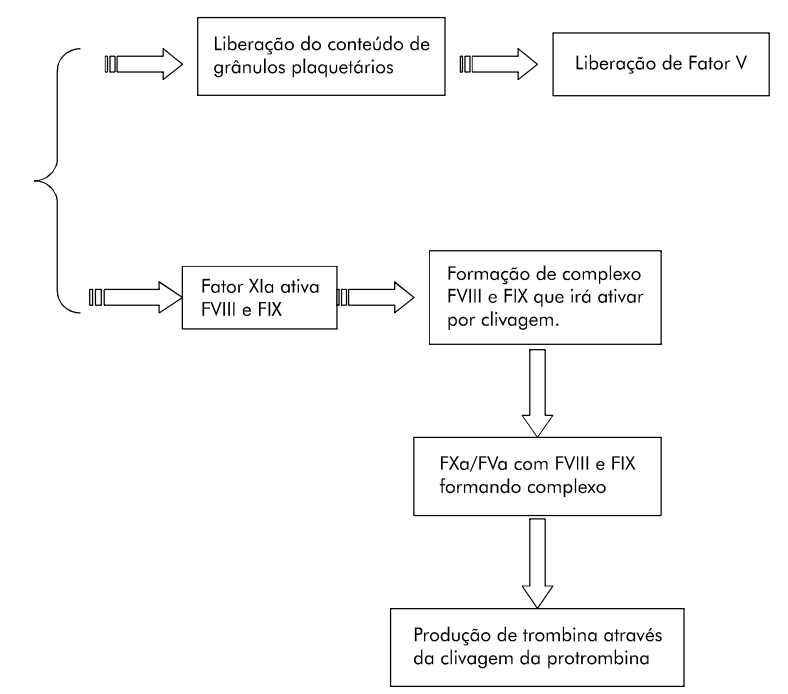

Figura 3. Hemostasia sanguínea normal 
de controle da ativação plaquetária. Entre os mecanismos relatados, tem-se a carga elétrica plaquetária e endotelial que vai gerar um campo que afasta a plaqueta do endotélio, a produção de óxido nítrico e PGI2 pelas células endoteliais (que terá ação não só vasodilatadora como também inibidora da ativação plaquetária) e, por fim, a produção e a liberação de uma enzima (ADAMTS 13), que irá clivar os multímeros do fator de von Willebrand $(\mathrm{vW})$ produzido em fragmentos menores com menor capacidade de adesão.

Em situações normais, o fator é liberado de duas maneiras. A primeira é de forma constante, ou seja, parte do $\mathrm{vW}$ produzido pelo endotélio e plaquetas é prontamente liberado após sua produção em multímeros, que são rapidamente clivados em fragmentos menores e menos aderentes. Na segunda forma, o fator é armazenado em grânulos plaquetários, porém em sua forma de maior peso (e com maior aderência) e no caso de estresse com ativação plaquetária, estes grânulos irão liberar no local da lesão uma grande quantidade de multímeros de von Willebrand.

Com o estresse/dano endotelial, o von Willebrand local é exposto e irá aderir aos receptores GpIb da plaqueta (Figura 2). No momento em que a plaqueta inicia a adesão ao fator, inicia-se uma ativação parcial com aumento do cálcio intracitoplasmático. Conseqüentemente, os grânulos plaquetários (grânulos alfa) irão liberar seu conteúdo no meio exterior. Deste conteúdo pode-se citar o fator von Willebrand de alto peso (multímero) e a Trombospondina-1. A última irá ligar-se ao ADAMTS 13 inibindo sua ação de clivagem do von Willebrand. Como conseqüência, irá acumular, no local da injúria, multímeros de $\mathrm{vW}$ com maior poder de aderência plaquetária de modo a fazer a ponte entre $o$ vaso e as plaquetas, e entre plaquetas ${ }^{13}$.

No entanto, no grânulo plaquetário também ocorre a presença de fator $\mathrm{V}(\mathrm{FV})$ parcialmente ativado que, por sua vez, ao ser liberado irá gerar trombina no local da lesão. Esta pequena quantidade de trombina gerada pela plaqueta terá um papel fundamental na ativação máxima das plaquetas, até então, apenas parcialmente ativadas. A trombina produzida, no entanto, é rapidamente inibida pela antitrombina ou pelo heparan e trombomodulina ligados ao endotélio.

Durante a fase de agregação plaquetária (o von Willebrand só tem papel vital na adesão em casos arteriais), nos leitos venosos (onde o fluxo tem menor velocidade), outras moléculas, como o fibrinogênio, têm um papel semelhante ao do von Willebrand através do receptor GPIIb-IIIa. Porém, em ambos os casos, para que haja adesão firme das plaquetas, é necessária a ligação de moléculas de adesão (como a ICAM-1) e do colágeno nos receptores plaquetários (como o $\mathrm{aIIb} \beta_{3}$ ).

$O$ receptor GPIb gera também um pico inicial (transitório) dos níveis intraplaquetários de cálcio; este pico irá auxiliar na parada da plaqueta e ativação inicial; porém, para que ocorra uma adesão plaquetária firme, há a necessidade de subseqüente oscilação sustentada do cálcio (que pode estar relacionada com a interação da adenosina di-fosfato (ADP) liberada pelos grânulos densos plaquetários com seu receptor ${ }^{13,14}$.

\section{HEMOSTASIA SECUNDÁRIA}

Inicia-se então a ativação da cascata de coagulação, na qual o estímulo inicial ocorre através da ativação da via do fator tecidual (FT) que está presente no subendotélio, nos fibroblastos, nos monócitos, entre outros tipos celulares. O FT ao entrar em contato com fator VII (FVII) promoverá sua ativação (FVIIa) por proteases, tanto da via da coagulação como por proteases não diretamente ligadas à coagulação (Figura 2).

Ocorre, então, a formação do complexo formado pelo FT e pelo FVIIa (complexo FT/FVIIa), que irá ativar o fator X (FX), o primeiro componente da via comum, e o fator IX (FIX).

O FXa terá uma ação local (junto às plaquetas), uma vez que o FXa que se difundir será inativado pela antitrombina (AT) $)^{15}$. Por outro lado, o FXa associado com o fator tecidual e FVIIa ativarão o fator V (FV), e a associação entre estes dois fatores na superfície endotelial irá gerar uma pequena quantidade de trombina (que não é suficiente para clivar o fibrinogênio em fibrina na ferida, mas é importantíssimo para a amplificação do primeiro sinal).

O complexo inicial (gatilho) formado pelo FT e o FVIIa é, então, inibido rapidamente pela via inibidora do fator tecidual.

$\mathrm{Na}$ fase de propagação (Figura 3), a pequena quantidade de trombina produzida inicialmente liga-se às plaquetas aderidas aos componentes da matriz subendotelial no sítio da injúria (von Willebrand e colágeno). A trombina aumenta a ativação da plaqueta (que previamente estava apenas parcialmente ativada) através dos receptores ativados por proteases (PAR). Esta dupla estimulação terá um efeito final sinérgico. A trombina também cliva o fator VIII (FVIII), liberandoo de sua ligação do von Willebrand (este fator, se não for rapidamente ativado e unir-se ao FIXa, será degradado), além de ativar pequena quantidade de fator IX, e o fator XI (FXI) ligado à superfície plaquetária.

O FX então é recrutado e ativado pelo complexo FVIIIa/FIXa na superfície da plaqueta e ativado (complexo tenase). O papel do complexo formado é também de proteger o FXa de ser inibido pela via 
inibidora do fator tecidual e pela antitrombina. $\mathrm{O}$ complexo FVIIIa/FIXa e FXa (também denominado complexo protrombinase) irá ativar $\mathrm{FV}$, e a associação entre FXa e FVa na superfície plaquetária terá como consequiência a produção de trombina, a partir da protrombina, de forma suficiente a formar o coágulo branco (ou coágulo estável).

A pequena quantidade de trombina gerada na fase de iniciação é inibida em menos de 1 minuto, caso não encontre um ambiente protetor. Porém, as plaquetas inativadas parecem ter três sítios de ligação para a trombina (complexo GP Ib-IX-V): o segundo sítio é o PAR-1, enquanto que o terceiro é no mesmo PAR ou vizinhos que irão, por sua vez, disparar a cascata de sinalização das plaquetas ${ }^{14}$.

No momento da estimulação plaquetária ocorre a liberação de FV parcialmente ativo dos grânulos plaquetários, que serão clivados pela trombina levando à produção de $\mathrm{FVa}$.

Se por um lado a injúria dispara o mecanismo de coagulação, à medida que os fatores de coagulação vão sendo ativados, estes passam a estimular a via inibidora da coagulação e proteolítica, de modo que o evento seja autolimitado e logo interrompido ${ }^{12}$.

A coagulação pode ser inibida tanto pelas proteínas inibidoras dos fatores de coagulação (proteínas C e S) ${ }^{16-18}$ que agirão inativando os fatores $\mathrm{V}$ e VIII, quanto pela antitrombina que age aumentando a degradação da fibrina e inibindo diretamente a trombina e pela transformação de plasminogênio em plasmina (que, por sua vez, agirá na fibrina clivando-a e conseqüentemente destruindo o coágulo). Outros inibidores da coagulação conhecidos são: o inibidor da via do fator tecidual (que irá inibir o FT e os fatores VIII e X ativados), co-fator II $\mathrm{da}$ heparina, inibidor $\mathrm{C} 1 \mathrm{da}$ esterase, a $\alpha 2$ macroglobulina e inibidor da al proteinase ${ }^{11}$.

A antitrombina tem uma importância particular, por sua capacidade de bloquear a ação da trombina, do FIXa, FXa e FXIa. Esta inativação não é rápida, permitindo que a trombina produza fibrina antes de ser inativada através da formação do complexo enzima-antitrombina. Por outro lado, a grande concentração de antitrombina no sangue impedirá que a trombina se espalhe para regiōes fora da lesão, levando à uma ativação da coagulação em locais fora do necessário.

A trombina, quando associada com a trombomodulina (um cofator ligado à membrana plaquetária) mudará a sua especificidade (esta mudança de especificidade está relacionada à mudança na conformação dos sítios catalíticos da enzima), deixando de ter atividade pró-coagulante (ativando FXI e clivando o fibrinogênio) ${ }^{19}$ e passará a ter uma atividade anticoagulante no momento em que começará a ativar a proteína $C$, clivando o seu zimogênio. A proteína $C^{17,18}$, por sua vez, associada com seus cofatores (proteína $\mathrm{S}$ e fator $\mathrm{V}$ ) vai inibir a coagulação inativando o $\mathrm{FVa}$ e o FVIIIa $^{16}$.

\section{ESTADO TROMBOFÍLICO NO CÂNCER}

O estado trombofílico no paciente com câncer não se caracteriza por uma alteração única na hemostasia causada pela célula da neoplasia, mas por uma interação entre a célula da neoplasia e o sistema hemostático que pode ser dividida em duas categorias gerais.

A primeira categoria consiste na síntese de mediadores (peptídeos ou polipeptídios), entre os quais se destacam as moléculas pró-coagulantes como o fator tecidual (FT), o pró-coagulante neoplásico $(\mathrm{CP})$, cuja expressão pode estar relacionada à produção de citocinas inflamatórias, como a interleucina $1 \beta$ (IL-1 $\beta$ ) e o fator de necrose tecidual (TNF $\alpha$ ) e pode levar à produção de substâncias pró-angiogênicas, como o fator de crescimento de endotélio vascular (VEGF). As citocinas produzidas pelas células neoplásicas (TNF e IL-1) irão agir, estimulando as células endoteliais íntegras e os monócitos a expressarem o FT em sua membrana externa, levando à ativação da cascata de coagulaçãao, ${ }^{40-23}$. No entanto, além de produzir mediadores pró-coagulantes, algumas neoplasias também produzem moléculas fibrinolíticas, como o ativador do plasminogênio tecidual (t-PA), a urokinase, ativadora do plasminogênio (u-PA) e inibidores do ativador do plasminogênio ${ }^{24}$.

A segunda categoria é a interação direta célula/célula resultando na ativação das células endoteliais, plaquetas e monócitos pelas células neoplásicas, levando, desse modo, à inibição da atividade anticoagulante e ao aumento da atividade pró-coagulante ${ }^{22,25}$.

\section{AsSOCIAÇÃO ENTRE TROMBOSE E NEOPLASIA}

Armand Trousseau (1801-1867) foi o primeiro a mostrar a relação entre câncer e trombose, através da observação do aparecimento de trombose venosa em pacientes com suspeita de neoplasia. No entanto, devido à deficiência de métodos diagnósticos eficazes na época, essa observação não pôde ser comprovada. Coincidentemente, como descreve Illtyd James e Matheson, em $1935^{26,27}$, o próprio Trousseau faleceu devido a tumor de estômago, tendo apresentado um evento de tromboflebite ao diagnóstico inicial da neoplasia. Illtyd James e Matheson também foram os primeiros, utilizando-se de métodos diagnósticos mais eficazes, a descreverem a relação entre câncer e trombose. Assim, através de estudos retrospectivos, em análise baseada em dados epidemiológicos e estudos 
prospectivos, foi possível obterem-se informações mais consistentes com relação ao diagnóstico de trombose no paciente portador de neoplasia.

Os primeiros achados que sugeriram a correlação entre trombose e cânceres vieram de estudos avaliando pacientes com trombose venosa profunda idiopática, e demonstraram que cerca de $10 \%-20 \%$ desses pacientes iriam ter um posterior aparecimento de neoplasia, enquanto que, naqueles com trombose venosa profunda, com causa predisponente definida, a incidência no aparecimento de neoplasia seria igual à encontrada na população em geral. Ou seja, em pacientes com trombose venosa idiopática houve um aumento na incidência de neoplasia em relação a outras populaçôes, que variou de 3 a 19 vezes de acordo com o estudo ${ }^{10,26-28}$. Tal variação na incidência pode estar relacionada com a sensibilidade dos métodos de pesquisa utilizados.

De modo a justificar os achados acima, baseandose nos estudos da fisiologia celular, acredita-se que, desde o aparecimento da primeira célula neoplásica até os sintomas do câncer (possibilidade de detecção), pode haver um espaço de, pelo menos dois anos, podendo chegar em alguns casos a 8 anos. Isto pode justificar os relatos do surgimento de eventos trombóticos de até 3 anos antes do diagnóstico da neoplasia. Considerando o fato descrito, o evento do tromboembolismo idiopático pode ser o primeiro sinal da presença de uma neoplasia, oculta ou não. Assim, é amplamente aceito que existe uma maior incidência de neoplasia naqueles pacientes que tiveram trombose de origem idiopática do que na população normal, havendo com isso um risco de desenvolver câncer, que pode chegar a 20\% nesses pacientes. Estudos avaliando a importância do tipo de screening ideal para esses pacientes falharam em chegar a um acordo, uma vez que não se definiu o quanto deve ser pesquisada, levando em consideração os custos (morbidade versus benefício) desses métodos de avaliação, sendo atualmente sugerido que não se deve fazer um screening invasivo nos pacientes com trombose idiopática, uma vez que, apesar de levar a um diagnóstico mais precoce, no entanto não melhorou o prognóstico ${ }^{29}$.

As evidências que suportam a relação entre trombose e neoplasia não se restringem apenas à incidência de eventos trombóticos em pacientes com câncer, mas também ao fato de que pacientes com trombose e câncer têm uma neoplasia de comportamento mais agressivo do que aqueles que não apresentaram fenômenos de trombose (o evento trombótico pode ser um marcador de agressividade da célula neoplásica), sendo estes achados bem descritos em dois estudos.

No primeiro, foram comparados tanto a freqüência de trombose venosa profunda como o índice de mortalidade em 1.211.944 pacientes portadores de neoplasias e 8.177.634 pacientes sem neoplasias, do registro $\mathrm{MEDCARE}^{30}$. O estudo mostrou que os pacientes portadores de neoplasia têm um aumento da probabilidade cumulativa de óbito nos subseqüentes 6 meses $(0,94)$ quando comparados com os pacientes sem câncer com trombose venosa profunda $(0,29)$ e em pacientes com câncer sem trombose venosa profunda $(0,42)$. No segundo estudo, Sørensen mostrou não só a alta freqüência de eventos trombóticos, como também que o grupo de pacientes que teve trombose no intervalo entre 1 ano antes até um ano após o diagnóstico da neoplasia (independente do tipo) teve uma sobrevida estaticamente menor $^{28}$.

\section{PAPEL DO PRó-COAGULANTE NEOPLÁSICO NA TROMBOSE EM PACIENTES COM CÂNCER}

O fator pró-coagulante neoplásico é uma cisteína protease, expressa apenas em tecidos neoplásicos e em tecido fetal humano, que ativa diretamente o fator $\mathrm{X}$, não necessitando da prévia ativação do fator VII. Existem vários tipos de pró-coagulantes neoplásicos, que podem ser encontrados nas células dos diferentes cânceres. De modo interessante, a freqüência de detecção do CP é maior em neoplasias em estágios iniciais (podendo chegar a 70\%) do que em neoplasias em estágios avançados $(20 \%)^{5}$.

$\mathrm{Na}$ leucemia pró-mielocítica, o CP está presente em grande quantidade, sendo responsável pelo estado trombofílico desta; o uso de ácido all-transretinóico associado à quimioterapia pode fazer com que haja a inibição da atividade protease (CP).

Por outro lado, o reaparecimento da atividade cisteína protease pode preceder o aparecimento clínico da recidiva da doença? .

\section{PAPEL dA EXPRESSÃO DO FATOR TECIDUAL NO APARECIMENTO DE TROMBOSE E BIOLOGIA DA CÉLULA NEOPLÁSICA}

Em 1834, Blaineville descreveu que a injeção venosa de suspensão de cérebro em animais foi imediatamente letal, ocluindo os vasos sanguíneos com coágulos. Este ensaio foi reproduzido posteriormente, com a injeção de extrato de vários tipos celulares em diferentes animais. Em 1905, Morawitz postulou haver duas fontes da produção de enzima que denominou tromboquinase, que catalisaria a transformação de protrombina em trombina. A primeira fonte seriam os leucócitos e as plaquetas (durante a injúria vascular ou estagnação sanguínea), e a segunda seria o tecido exposto, após a injúria tecidual. A partir destes achados, e melhor conhecimento da coagulação, foi identificado o fator tecidual ${ }^{31}$.

Este talvez seja um dos agentes mais interessantes e 
mais bem estudados, devido não só à sua ação na coagulação normal e no evento da trombose em câncer, como também pelo seu efeito na biologia celular ${ }^{32}$. Um indicador da ação deste na biologia celular vem da grande similaridade estrutural do fator tecidual com a superfamília de receptores de citocinas, o que sugere que os genes que originam cada um podem ter um ancestral comum.

O fator tecidual é uma proteína transmembrana que, além de ter papel na ativação da coagulação, também assume um papel importante em vários outros fenômenos fisiológicos, como: na angiogênese $e^{33}$, através da produção de fator de crescimento e cicatrização de ferida, no processo de proliferação e diferenciação das glândulas mamárias e na diapedese de leucócitos durante a inflamação. Por outro lado, o fator tecidual também tem papel em vários fenômenos patológicos, como na angiogênese oncogênica, progressão da sepsis letal por E coli. ${ }^{25,31,34}$ e na trombose desencadeada pelas células que entram em apoptose (já que a apoptose estimula a produção de citocinas que vão aumentar a sua expressão ${ }^{35}$ ).

No entanto, para que ocorra a transdução da maioria dos sinais dependentes do FT é necessário que haja, inicialmente, a interação do fator tecidual com o fator VII ativado. Essa interação geraria um sinal que, posteriormente, seria transduzido através da membrana celular ${ }^{32}$.

O papel do fator tecidual na formação da metástase ainda não é bem entendido, no entanto, parece haver uma íntima relação entre ele e a produção de fator de crescimento de endotélio (VEGF), um dos responsáveis pela angiogênese normal e importantíssimo na formação de neovasos, para permitir o crescimento da neoplasia ${ }^{36}$. Uma vez que, tanto o fator tecidual pode levar a um aumento do VEGF, como o segundo pode estimular a expressão do primeiro, acredita-se que exista uma via comum de regulação do VEGF e fator tecidual ${ }^{20,32,33,37}$.

O fator tecidual é expresso na superfície celular de vários tumores, particularmente naqueles de origem epitelial, sendo que, em vários cânceres, a sua expressão está relacionada com o grau histológico de malignidade, invasividade tumoral, resistência a múltiplas drogas e prognóstico ${ }^{33,37-39}$. Entretanto, em alguns tumores, como o de mama e nos gliomas, os resultados são conflitantes. Um outro importante achado é que o fator tecidual é mais observado no tumor metastático, que por sua vez é mais angiogênico que o primário ${ }^{33,37}$. No entanto, a ação trombogênica e angiogênica do fator tecidual pode ser inibida por substâncias como a Angiopoietina-1 (Angio-1) ${ }^{40}$.

\section{FORMAÇÃO DA TROMBINA DURANTE A ATIVAÇÃO DA COAGULAÇÃO E SEU PAPEL NA EVOLUÇÃO DO CÂNCER}

A trombina, produzida no estado trombofílico do paciente com câncer, também tem papel na progressão da neoplasia de diversas formas. Gerando um aumento da adesividade das células neoplásicas, conseqüentemente leva a um maior potencial metastático. A trombina, por sua vez, não só gera a agregação plaquetária (que, entre outras coisas, servirá para impedir o acesso do sistema imunológico à célula neoplásica durante a disseminação deste), como estimula a síntese do FT e a produção de fibrina a partir do fibrinogênio ${ }^{20,41}$.

A ação direta da trombina na angiogênese ocorre através da indução do aumento da produção tanto do VEGF como de seus receptores no endotélio vascular ${ }^{20,37}$.

\section{Papel dO VEgF nO CREsCimento TUMORAL}

A observação de que o crescimento tumoral é acompanhado pela proliferação vascular foi feita há mais de 100 anos, levando os autores a criarem a hipótese de que esta neovascularização facilitaria o crescimento do tumor, através da oferta de nutrientes e oxigênio, além de remover catabólitos. Em 1945, Algire e Chalkley ${ }^{41,42}$, que iniciaram a quantificação de vasos associados ao crescimento tumoral, verificaram que a fase de crescimento acelerado do tumor é precedida por um aumento local da densidade de vasos. Por fim, em 1970, Folkman propôs que a antiangiogênese poderia ser um método eficaz de controle da neoplasia.

$O$ achado de que o aumento da angiogênese modulada pelo VEGF está relacionado com o crescimento tumoral foi verificado tanto em tumores sólidos quanto em tumores hematológicos ${ }^{41-43}$.

O fator de crescimento de endotélio vascular (VEGF) tem múltiplas açōes nas células endoteliais, agindo como um mitógeno específico nas veias, artérias e linfáticos e como fator inibidor da apoptose (através de estimulação da produção da proteína antiapoptótica $\mathrm{Bcl}-2$, nestas células). O VEGF também pode afetar a permeabilidade do endotélio, porém para sua ação angiogênica não é necessário que ocorra a ação de aumento de permeabilidade endotelial ${ }^{41,37}$.

\section{Papel da CICATRIZAÇ̃̃o CIRÚRgica e hIPóxIa Na NeO- ANGIOGÊNESE E ANGIOGÊNESE TUMORAL}

$\mathrm{Na}$ cicatrização da ferida cirúrgica, um fator importante é a produção de novos vasos, gerando assim, um suprimento sanguíneo local. Desse modo, não é de se estranhar que, no pós-operatório, os níveis de VEGF estejam aumentados. No entanto, a ação desse VEGF não é somente localizada no local da ferida, mas também em vários outros locais. Evidências clínicas e laboratoriais mostraram um aumento no crescimento de metástases residuais (principalmente metástases localizadas na ferida operatória ou em anastomoses) no 
pós-operatório da retirada de tumor, após o clampeamento vascular para retirada de tumores e nas cirurgias feitas em dois tempos, quando comparadas àquelas feitas em apenas um tempo ${ }^{44}$.

\section{PAPEL DA QUIMIOTERAPIA NO APARECIMENTO DA TROMBOSE}

Além dos fatores previamente descritos para o aparecimento da TVP em pacientes com câncer, estudos já demonstraram que a quimioterapia em pacientes portadores de câncer (principalmente o uso de fluoracil associado com ácido folínico, em pacientes com câncer de cólon e tamoxifeno nos pacientes com câncer de mama) está relacionada com um aumento adicional na incidência de trombose $\mathrm{e}^{45}$. $\mathrm{O}$ real mecanismo para o desenvolvimento da trombose ainda é discutido, porém já é amplamente aceita esta associação.

Uma hipótese levantada para a relação quimioterapia e trombose está na formação de micropartículas apoptóticas (Figura 4). É conhecido que a maioria dos quimioterápicos induzem à morte celular através da apoptose (morte celular programada).

Nas células normais (fora do processo de apoptose), a organização das camadas de lipídeos da membrana externa não deixa exposta uma classe de lipídeos

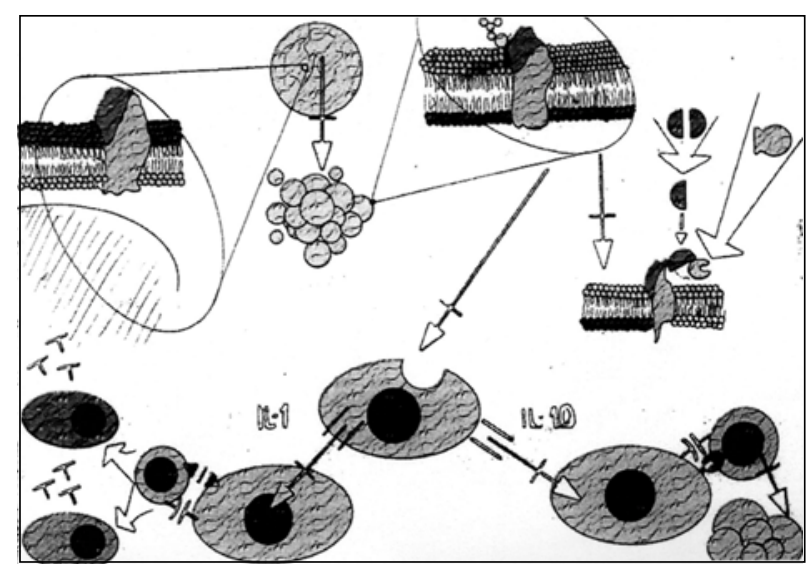

Figura 4. Quimioterapia e trombose aniônicos, a fosfatidil serina (FS), que tem capacidade de induzir o início da coagulação, além de poder gerar uma resposta imunológica ${ }^{46}$.

No entanto, um dos primeiros eventos verificados, quando a célula entra em apoptose é a desestruturação da camada de lipídeos (possivelmente gerada pela oxidação do colesterol de membrana) ${ }^{47}$ que fará com que a FS passe a ser expressa no exterior da célula, entrando em apoptose. Essa expressão de FS fará com que se inicie o acúmulo de trombina na região. Verificouse que a adição de Anexina V (que se liga à FS) irá inibir a formação de trombina. Um dos mecanismos de tentar impedir essa ativação da coagulação será através do depósito de proteína $S$ na camada lipídica ${ }^{46,48-50}$.

A FS, porém, tem um efeito de marcar o corpo apoptótico de modo a poder ser fagocitado pelos macrófagos e outras células fagocíticas ${ }^{51}$. No entanto, após fagocitado, esse corpo apoptótico poderá levar a uma expressão de seu material (inclusive a FS) junto com o antígeno de histocompatibilidade da célula (HLA) e, dependendo do estímulo associado, pode gerar uma resposta de tolerância (destruição de linfócitos autoreativos) ou resposta imune completa com a produção de auto-anticorpos contra fosfolipídeos (antifosfolipídeos). Os antifosfolipídeos, principalmente da classe do anticoagulante lúpico, e os anticardiolipina que se ligam à beta 2 -glicoproteína 1 (ß2-GP1) irão levar a um estado de hipercoagulabilidade associado (figura 5$)^{52-54}$.

\section{CONCLUSÃO}

A trombose em pacientes com neoplasia, que já foi considerada apenas como uma complicação secundária à cirurgia ou ao período de restrição no leito, recentemente mudou completamente seu foco. Nos dias atuais, acredita-se que a ativação da coagulação é um fenômeno gerado diretamente ou indiretamente pelas células neoplásicas, de modo a gerar um ambiente propício para o seu crescimento. A ativação da

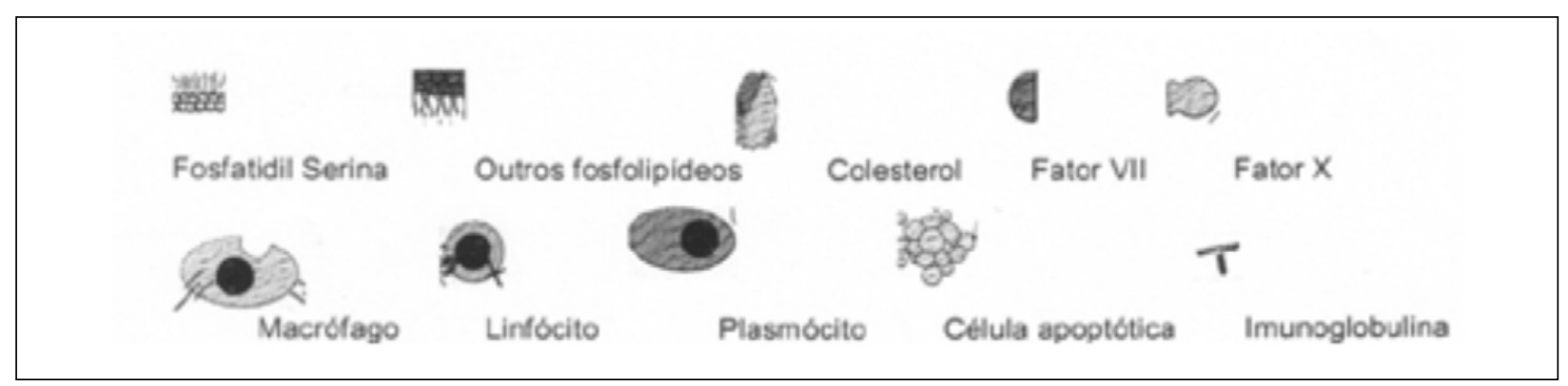

Figura 5. Papel das micropartículas (corpos apoptóticos) na indução da trombose e formação de anticorpos antifosfolipídeos 
hemostasia age tanto através da produção de novos vasos que irão suprir o crescimento tumoral quanto à ativação de receptores ativados por enzimas (no caso trombina), responsáveis por modular várias atividades celulares importantes. Nesse caso, a trombose seria nada mais do que a atividade excessiva do sistema hemostático com conseqüiente formação do trombo.

Clinicamente os achados descritos são verificados através de um aumento na freqüência de tromboses em pacientes portadores de neoplasias em relação àqueles sem câncer, e uma associação de neoplasias mais agressivas e menor sobrevida naqueles pacientes com neoplasia que apresentaram trombose, se comparados aos pacientes com o mesmo tipo de câncer, porém sem um diagnóstico de fenômeno trombótico.

\section{AGRADECIMENTO}

Agradeço ao Prof. Robson Queiroz Monteiro pelo apoio, com discussões sobre o assunto e sugestôes de literatura, à equipe do setor de Hematologia e Chefia do Laboratório de Patologia Clínica do HCI / INCA pelo auxílio nos protocolos de pesquisa e disponibilização de tempo para as revisóes.

Agradeço também à Fundação Ary Frauzino para o Combate ao Câncer e ao Instituto Nacional de Câncer pelo suporte institucional.

\section{REFERÊNCIAS}

1. Seligsohn V, Lubetsky A. Genetic suscebility to venous thrombosis. N Engl J Med. 2001;344(16):1222-231.

2. Blom JW, Doggen CJ, Osanto S, Rosendaal FR. Old and new risk factors for upper extremity deep venous thrombosis. J Thromb Haemost. 2005;3(11):2471-478.

3. Blann AD, Lip GY. Virchow's triad revisited: The importance of soluble coagulation factors, the endotelium and platelets. Thromb Res. 2001;101(4):323-27.

4. Hillen HF. Thrombosis in cancer patients. Ann Oncol. 2001;11(suppl 3):273-76.

5. Hoffman R, Haim N, Brenner B. Cancer and thrombosis revisited. Blood Rev. 2001;15(2):61-67.

6. Bick RL, Strauss JF, Frenkel EP. Thrombosis and hemorrhage in oncology patients. Haematol Oncol Clin North Am. 1996;10(4):876-907.

7. Marras LC, Geerts WH, Perry JR. The risk of venous thromboembolism is increased throughout the course of malignant glioma. An evidence based review. Cancer. 2000;89(3):640-43.

8. Oya M, Akiyama Y, Okuyama T, Ishika'> H. High preoperactive plasma $\mathrm{D}$-dimer level is associated with advanced tumor stage and short survival after curative resection in patients with colorectal cancer. Jpn J Clin Oncol. 2001;31(8):388-94.

9. Rickles FR, Levine MN. Epidemiology of thrombosis in cancer. Acta Haematol. 2001;106(1-2):6-12.

10. Piccioli A, Prandoni P. Venous thromboembolism as first manifestation of cancer. Acta Haematol. 2001;106(12):13-17.

11. Greenberg CS, Orthner CL. Blood coagulation and fibrinolysis. In Lee GR, Foerster J, Lukens J, Paraskevas F, Greer JP, Rodgers GM. Withrobe's clinical haematology. 10th ed. Baltimore: Williams \& Wilkins; 1999:684-764.

12. Monroe DM, Hoffman M, Roberts HR. Platelets and thrombin generation. Arterioscler Thromb Vasc Biol. 2002;22(9):1381-389.

13. Ruggeri ZM. Von Willebrand factor, platelets and endotelial cell interations. J Thromb Haemost. 2003;1(7):1335-342.

14. RufW, Dorflentner A, Riewald M. Specificity of coagulation factor signaling. J Thromb Haemost. 2003;1(7):1495-503.

15. Mast AE, Broze Jr GJ. Physiological concentrations of tissue factor pathway inhibithor do not inhibit phrothrombinase. Blood. 1996;87(5):1845-850.

16. Davie EW, Fujikawa K, Kisiel W. The coagulation cascade: initiation, maintance and regulation. Biochemistry. 1991;30(43):10363-10370.

17. Dahlback B, Villoutreix BO. Molecular recognition in the protein $\mathrm{C}$ anticoagulant pathway. J Thromb Haemost. 2003;1(7):1525-534.

18. Esmon CT. Regulation of blood coagulation. Biochim Biophhys Acta. 2000;1477(1-2):349-60.

19. Weiler H, Isermann BH. Thrombomodulin. J Thromb Haemost. 2003;1(7):1515-524.

20. Bromberg ME, Cappello M. Cancer and blood coagulation: molecular aspects. Cancer J Sci Am. 1999;5(3):132-38.

21. Leone G, Sica S, Chiusolo P, Teofili L, De Stefano V. Blood cell diseases and thrombosis. Haematol.2001;86(12):1236-244.

22. Rickles FR, Falanga A. Molecular basis for the relationship between thrombosis and cancer. Thromb Res. 2001;102(6):V215-V24.

23. Gale AJ, Gordon SG. Update on tumor cell pro coagulant factors. Acta Haematol. 2001;106(1-2):25-32.

24. Dano K, Behrendt N, Heyer-Hansen G, Johnsen M, Lund LR, Ploug M, et al. Plasminogen activation and cancer. Thromb Haemost. 2005;93(4):676-81.

25. Chen J, Bierhaus A, Schiekofer S, Andrassy M, Chen B, Stern DM, et al. Tissue factor. A receptor involved in the control of cellular proprieties, including angiogenesis. Thromb Haemost. 2001;86(1):334-51.

26. Otten HM, Prins MH. Venous thromboembolism and occult malignancy. Thromb Res. 2001;102(6):V187-V94.

27. Levine MN, Lee AY, Kakkar AK. From Trusseau to target therapy: new insights and innovations in thrombosis and cancer. J Thromb Haemost. 2003;1(7):1456-463. 
28. SÆrensen HT, Mellemkjaer L, Olsen JH, Baron JA. Prognoses of cancer associated with venous thromboembolism. N Engl J Med. 200;343(25):1846-850.

29. Piccioli A, Lensing AW, Prins MH, Falanga A, Scannapieco GL, Leran M, et al. PROMIT Investigators Group. Extensive screening for occult malignant disease in idiopathic venous thromboembolism: a prospective randomized clinical trial. J Thromb Haemost. 2004;2:884-89.

30. Levitan N, Dowlati A, Remick SC, Tahlsidar HI, Sivinski $\mathrm{LD}$, Beyth $\mathrm{R}$, et al. Rates of initial and recurrent thromboembolic disease among patients with malignancy versus those without malignancy: risk analysis using Medicare claims data. Medicine. 1999;78(5):285-91.

31. Bachli E. History of tissue factor. Br J Haematol. 2000;110(2):248-55.

32. Peppelenbosch MP, Versteeg HH. Cell biology of tissue factor, an unusual member of the cytokine receptor family. Trends Cardiovasc Med. 2001;11(8):335-45.

33. Zetter BR. Angiogenesis and tumor metastasis. Ann Rev Med. 1998;49:407-24.

34. Ferrara N, Gerber HP. The role of vascular endotelial growth factor in angiogenesis. Acta Haematol. 2001;106(4):148-56.

35. Wang J, Weiss I, Svoboda K, Kwaan HC. Thrombogenic role of cells undergouing apoptosis. Br J Haematol. 2001;115(2):382-91.

36. Bergers G, Benjamin LE. Tumorigenesis and the angiogenic switch. Nat Rev Cancer. 2003;3(6):401-10.

37. Wofturiecwicz MZ, Sierko E, Klement P, Rak J. The hemostatic sistem and angiogenesis in malignancy. Neoplasia. 2001;3(5):371-84.

38. Palumbo JS, Kombrinck KW, Drew AF, Grimes TS, Kiser $\mathrm{JH}$, Dergen JL, et al. Fibrinogen is an important determinant of the metastatic potential of circulating tumor cells. Blood. 2000;96(10):3302-309.

39. Ueda M, Teraei Y, Yamashita Y, Kumagai K, Veki K, Yamaguchi $\mathrm{H}$, et al. Correlation between vascular endotelial growth factor $\mathrm{C}$ expression and invasion phentype in cervical carcinomas. Int J Cancer. 2002;98(3):335-43.

40. Kim I, OH JL, Ryu YS, So JN, Sessa WC, Walsh K, et al. Angiopoietin-1 negatively regulates expression and activity of tissue factor in endotelial cells. FASEB J. 2002;16(1):126-28.

41. Plate KH. From angiogenesis to lymphoangiogenesis. Nat
Med. 2001;7(2):151-52.

42. Margi MH, Newland AC. Angiogenesis and angiogenic mediators in haematologic malignancies. $\mathrm{Br} \mathrm{J} \mathrm{Haematol.}$ 2000;111(1):43-51.

43. Keyhani A, Jandiroba DB, Freireich EJ. Angiogenesis and leukemia. Leuk Res. 2001;25(8):639-45.

44. van der Bilt JD, Borel Rinkes IH. Surgery and angiogenesis. Biochim Biophys Acta. 2004;1654(1):95-104.

45. Otten HM, Mathijssen J, Ten Cate H, Sorsan M, Ighels M, Richel DJ, et al. Symptomatic venous thromboembolism in cancer patients treatment with chemotherapy. Arch Int Med. 2004;164(2):190-94.

46. Casciola-Rosen L, Rosen A, Peri M, Schlissel M. Surface blebs on apoptotic cells are sites of enhanced procoagulant activity: Implications for coagulation events and antigenic spread in systemic lupus erytematosus. Proc Natl Acad Sci USA. 1996;93(4):1624-629.

47. Aupeix K, Toti F, Satta N, Bischoff P, Freyssenet JM. Oxysterols induce membrane procoagulant activity in monocyte THP-1 cells. Biochem J. 1996;314:1027-1033.

48. Flynn PD, Byrne CD, Baglin TP, Weissberg PL, Bennett MR. T generation by apoptotic vascular smooth muscle cells. Blood. 1997;89(12):4378-384.

49. Mallat Z, Hugel B, Ohan J, Leséche G, Freyssinet JM, Tedgui A. Shed membranes microparticles with procoagulant potential in human atherosclerotic plaques. Circulation. 1999;99(3):348-53.

50. Freyssinet JM. Cellular microparticles: what are they bad or good for? J Thromb Haemost. 2003;1(7):1655-662.

51. Fadok VA, Voelker DR, Campbell PA, Cohen JJ, Bratton DL, Hanson PM. Exposure of phophatidylserine on the surface of apoptotic lymphocytes triggers specific recognition and removal by macrophages. J Immunol. 1992;148(7):2207-216.

52. Galli M, Luciani D, Bertolini G, Barberi T. Anti- B2glycoprotein 1, antiprothrombin antibodies, and risk of thrombosis in the antiphospholipid syndrome. Blood. 2003;102(8):2717-723.

53. Levine JS, Branch DW, Rauch J The antiphospholipid syndrome. N Engl J Med. 2002;346(10):752-63.

54. Levy RA, de Meis E, Pierangeli S. Differentianting patogenic from non-pathogenic aPL by a beta2-glycoprotein I dependency anticardiolipin ELISA Assay. Thromb Res. 2004;114(5-6):573-77. 


\section{Abstract}

From Trusseau's theory on clotting to the present day, much information has been reported on blood clotting. With improved knowledge of related events using molecular, cellular, and clinical studies, there is agreement that clot production is not an isolated phenomenon, but part of a group of interrelated events that effect cell biology.

Currently, this relationship between the clotting system and cells (normal and abnormal) is known to be important for the genesis and evolution of many common diseases. In this context, great attention is focused on cancer and its biology.

The aim of this article is to demonstrate the new blood clotting theory and its regulation, and to demonstrate how clotting can interfere at the level of neoplastic cell biology and clinical outcome in cancer patients.

The model to demonstrate the results of this effect is one of the most frequent clinical conditions, namely the development of thrombosis.

Key words: Cancer; Clotting; Thrombosis 